\title{
POSSIBILITIES OF PROCESSING ARCHIVAL PHOTOGRAMMETRIC IMAGES CAPTURED BY ROLLEI 6006 METRIC CAMERA USING CURRENT METHOD
}

\author{
A. Dlesk ${ }^{1, *}$, P. Raeva ${ }^{1}$, K. Vach ${ }^{2}$ \\ ${ }^{1}$ Department of Geomatics, CTU in Prague - adam.dlesk@gmail.com \\ ${ }^{2}$ EuroGV s.r.o. - vach@eurogv.cz
}

Commission II, WG II/8

KEY WORDS: Rollei 6006 metric, Photo negatives, Structure from motion, Archival data, Close range photogrammetry

\begin{abstract}
:
Processing of analog photogrammetric negatives using current methods brings new challenges and possibilities, for example, creation of a 3D model from archival images which enables the comparison of historical state and current state of cultural heritage objects. The main purpose of this paper is to present possibilities of processing archival analog images captured by photogrammetric camera Rollei 6006 metric. In 1994, the Czech company EuroGV s.r.o. carried out photogrammetric measurements of former limestone quarry the Great America located in the Central Bohemian Region in the Czech Republic. All the negatives of photogrammetric images, complete documentation, coordinates of geodetically measured ground control points, calibration reports and external orientation of images calculated in the Combined Adjustment Program are preserved and were available for the current processing. Negatives of images were scanned and processed using structure from motion method (SfM). The result of the research is a statement of what accuracy is possible to expect from the proposed methodology using Rollei metric images originally obtained for terrestrial intersection photogrammetry while adhering to the proposed methodology.
\end{abstract}

\section{INTRODUCTION}

Processing of analog photogrammetric negatives using current methods brings new challenges and possibilities, for example, creation of a 3D model from archival images which enables comparison of historical state and current state of cultural heritage objects (Pavelka, 2017). Studies have shown that processing of analog images using current methods has huge potential in cultural heritage (Maiwald, 2017; Rodríguez Miranda, 2017). Authors of this paper have already collaborated with the Czech Research Institute of Geodesy, Topography and Cartography on processing of aerial analog images of Slovakian Tatra mountains and with Estonian company Archaeovision LLC on processing analog images of Padise Kloster captured by photogrammetric camera UMK/1318 with wide angle lens Super-Lamegon PI 5,6/64. The methodology of processing Rollei metric images is proposed in this paper: from the digitalization of each negative, through transformation and masking of réseau crosses to the creation of a textured 3D model in appropriate software. Detailed analysis will be done to determine what accuracy can be achieved by the proposed method. In 1994, the Czech company EuroGV s.r.o. carried out photogrammetric measurements of the limestone quarry Great America using close range intersection photogrammetry method. In the EuroGV archive, there are stored more than 170 negatives of photogrammetric images, extensive documentation, geodetically measured coordinates of more than 300 ground control points, external orientation of images then calculated in CAP (Combined Adjustment Program) and calibration reports of the used Rollei 6006 metric camera. All the data are usable for structure from motion (SfM) processing in Agisoft PhotoScan and analysis of the results.

\subsection{The Great America Quarry}

The Former quarry Great America is located in the Czech Republic, nearby the Mořina village, approximately $10 \mathrm{~km}$ from
Prague. The unique shape of the quarry resembles a canyon and is $750 \mathrm{~m}$ long, $150 \mathrm{~m}$ wide and at some places $80 \mathrm{~m}$ deep. Quarrying processes started in 1900 and ended in 1964 and now the quarry is protected.

\subsection{Original measurement and processing}

Photogrammetric measurement of the quarry's walls with mapping accuracy 1:500 was performed by the Czech company EuroGV s.r.o. in 1994 at the request of geologists. Close range intersection photogrammetry was chosen as a main method and for capturing images was used Rollei 6006 metric camera.
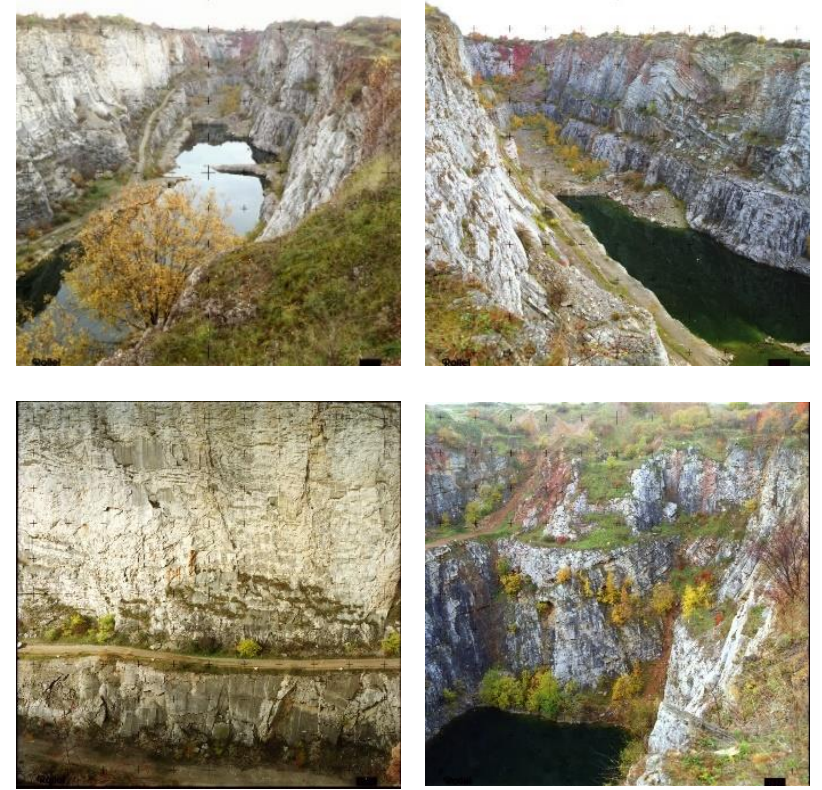

Figure 1. Limestone quarry the Great America on Rollei 6006 metric images. 
Throughout the whole area a photogrammetric targeting was made of wooden crosses and painted crosses on the quarry's walls. More than 300 ground control points (GCPs) were geodetically measured around the whole area of the quarry Great America for georeferencing.
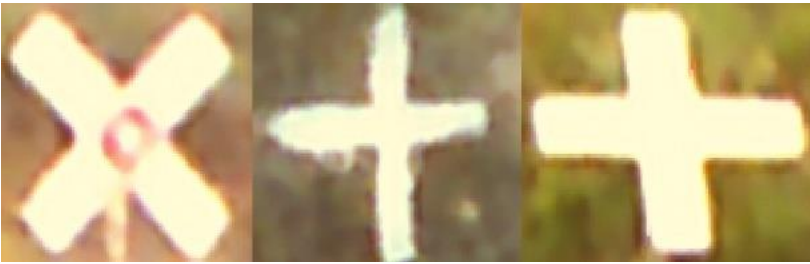

Figure 2. Photogrammetric targeting of ground control points on scanned Rollei 6006 metric images.

More than 170 photogrammetric images were captured by photogrammetric camera Rollei 6006 metric on a photographic film (dimension $6 \times 6 \mathrm{~cm}$ ). Two lenses were used for capturing. First one with $80 \mathrm{~mm}$ focal length and second one with $40 \mathrm{~mm}$ focal length. The photo negatives of Rollei 6006 metric images were enlarged and the photo prints had size $(30 \times 30 \mathrm{~cm})$. With usage of professional digital workstation were measured tie points on the images. The tie points with the GCPs were an input for intersection photogrammetry calculation using Rolleimetric MR2 software. Adjustment was processed in CAP (Combined Adjustment Program). Root mean square of adjustment for ground control points was $0,02 \mathrm{~m}$. Accuracy of measuring on image was $0,017 \mathrm{~mm}$. Then survey points were measured in $5 \times 5 \mathrm{~m}$ grid on quarry's walls. In some parts, survey points were measured in denser grid because of requirements for geologists. From the survey points a digital terrain model (DTM) of the quarry was created in the software Atlas DMT which is developed by the Czech company Atlas s.r.o.. Contours were computed and exported and height profiles on the DTM were made in specific parts. The profiles were exported into a CAD software.
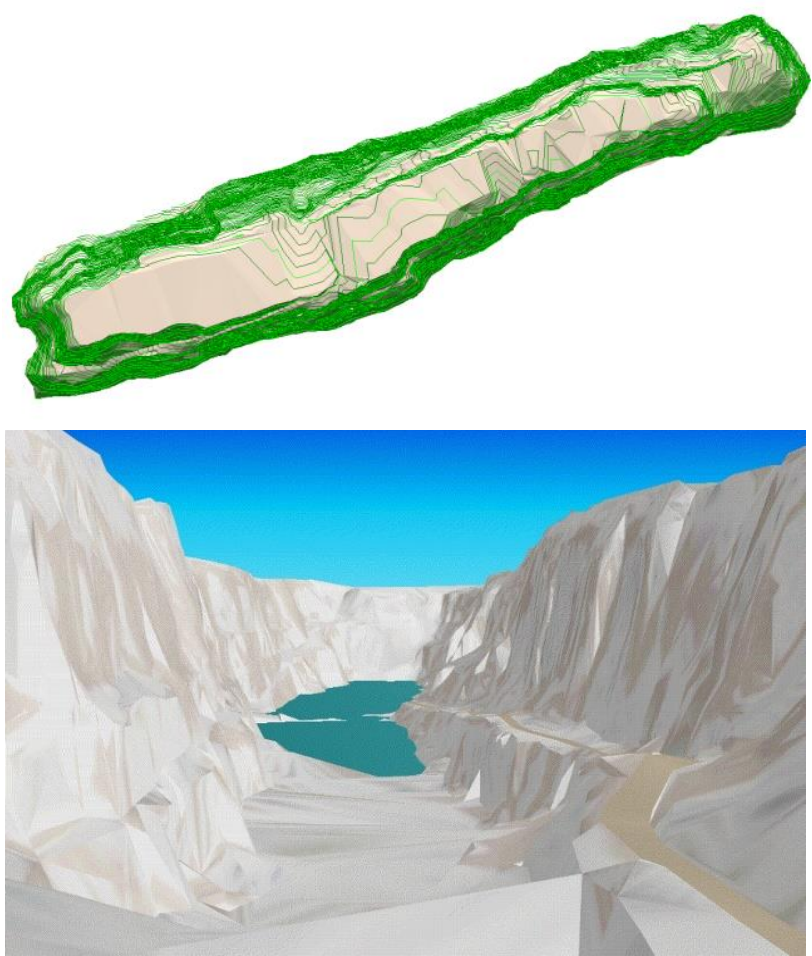

Figure 3. DTM created in 1994 using software Atlas DMT.
Negatives of images, measuring documentation, GCPs coordinates and full calibration reports for both lenses were archived.

\subsection{Camera Rollei 6006 metric}

The camera Rollei 6066 metric was a flexible and easy-to-use terrestrial photogrammetric camera developed and produced by the German company Rollei from Braunschweig. The camera is included in a group of cameras with the réseau principle. The camera has a réseau plate which is a planar glass plate with regular grid of réseau crosses. The crosses are projected on a photographic film and the crosses are used for definition of the image coordinate system and correction of photographic film deformation. In the case of Rollei 6006 metric camera a spacing between réseau crosses is approximately $5 \mathrm{~mm}$. With image format $6 \times 6 \mathrm{~cm}$ each image has 121 crosses. Their position is calibrated by the manufacturer using a test field calibration with an accuracy of $1 \mu \mathrm{m}$. It was possible to change lenses with Rollei metric cameras. Zeiss lenses with focal length $40 \mathrm{~mm}, 60 \mathrm{~mm}, 80$ $\mathrm{mm}$ and $150 \mathrm{~mm}$ were used. Besides the Rollei 6006 metric camera the company Rollei produced also Rollei 3003 metric camera for applications with lower accuracy requirements. The format of images was $36 \times 24 \mathrm{~mm}$ with 35 réseau crosses (Luhman, 2007). The Rollei 6006 camera played an important role in architectural photogrammetry (Styliadis, 2007) and the Rollei 6006 camera negatives are stored in many archives worldwide and have huge potential for processing with most modern methods.

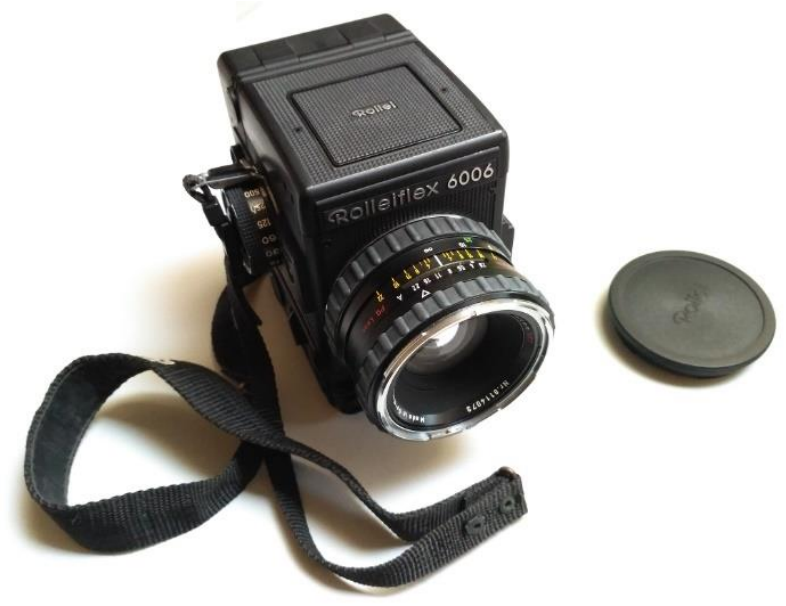

Figure 4. Camera Rollei 6006 metric.

\section{METHODOLOGY}

Methodology of scanning negatives, cropping the scanned images and their processing was proposed. For processing with use of Structure from motion method was chosen software Agisoft PhotoScan.

\subsection{Digitalization of negatives and their preparation for processing}

First, negatives were scanned with 4800 dpi resolution using CanoScan 9000F Mark II which is intended for professional scanning of photo negatives. For ordinary purposes it is sufficient to use non-photogrammetric scanner and we wanted to present methodology which can be used by institutions which have access to photogrammetric images but do not have access to photogrammetric scanner. For SfM processing it is important to achieve the same dimension in pixels for every image. Moreover, 
image coordinates of the principal point of every cropped image theoretically should have the same value. That is why each scanned negative was transformed to Rollei 6006 metric réseau crosses coordinates using 1. polynomial transformation. Even though the coordinates of principle point were not ideally the same but still with tolerance. The transformation also partly eliminates deformation of the negative (Pavelka 2011). Then each scanned image was cropped by the same created polygon. The result was a group of images with the same pixel size (10158x10158 pix) which responds approximately to $0,005 \mathrm{~mm}$ per pixel and each image had approximately the same principle point image coordinates.

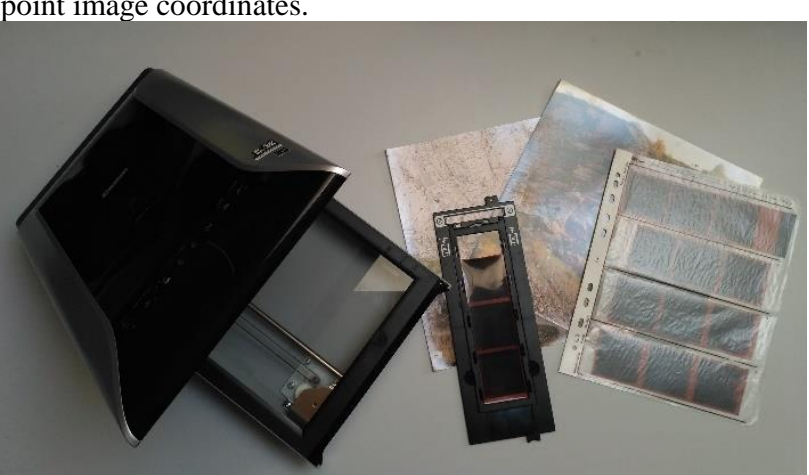

Figure 5. Digitalization of photogrammetric negatives.

\subsection{Processing of images}

The scanned preprocessed images were imported into Agisoft PhotoScan and divided into two groups, based on different focal lengths ( $40 \mathrm{~mm}-15$ images and $80 \mathrm{~mm}-163$ images). All images were processed together but for each group of images its pixel size and its different focal length from calibration protocol was set. To cover the réseau crosses, a mask was created and automatically applied to every image. The co-registration of images was computed, then 35 points were used as GCPs and bundle adjustment was done. The rest of 293 points were left as control points for further analysis.

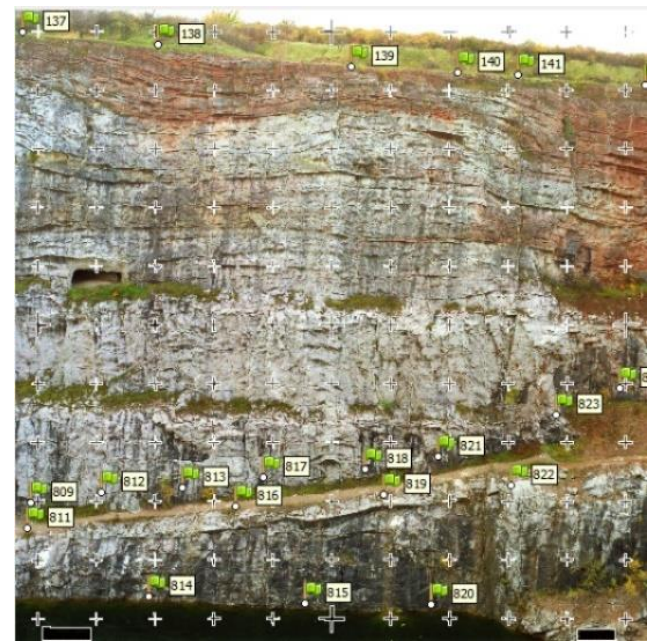

Figure 6. Distribution of GCPs and control points on image.

\section{ANALYSIS}

For the analysis, 293 points were measured on images and newly computed coordinates were compared to adjusted coordinates from former measurement in 1994. According to the following graph, $68 \%$ of distances in space between newly calculated points and calculated points in 1994 were under $5 \mathrm{~cm}$. 28\% of the distances in space were from $5 \mathrm{~cm}$ to $10 \mathrm{~cm}$. The rest of the distances were more than $10 \mathrm{~cm}$ but none of them exceeded $17 \mathrm{~cm}$. This accuracy corresponds to 1:500 mapping scale requirement.

\begin{tabular}{|l|l|}
\hline Mean [m] & 0.047 \\
\hline Median [m] & 0.041 \\
\hline Standard deviation [m] & 0.026 \\
\hline
\end{tabular}

Table 1. Statistic values of set of distances.

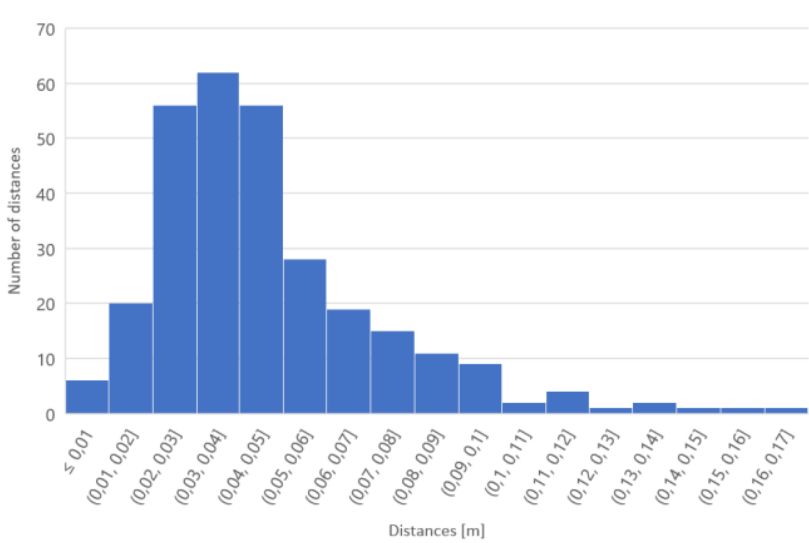

Figure 7. Histogram of the distances in space between newly calculated points and calculated points from former measurements.

After bundle adjustment, the interior orientation of both cameras was adjusted. The adjusted parameters of interior orientation were compared with parameters stated in camera calibration report.

\begin{tabular}{|c|c|c|c|}
\hline & $\begin{array}{c}\text { Calibration } \\
\text { protocol }\end{array}$ & $\begin{array}{c}\text { Calculated } \\
\text { value }\end{array}$ & $\Delta$ \\
\hline $\mathrm{f}[\mathrm{mm}]$ & 80.29 & 80.47 & 0.18 \\
\hline pp_x [mm] & 0.03 & 0.06 & 0.03 \\
\hline pp_y [mm] & 0.44 & 0.44 & 0.00 \\
\hline
\end{tabular}

Table 2. Results of camera calibration for $80 \mathrm{~mm}$ lens.

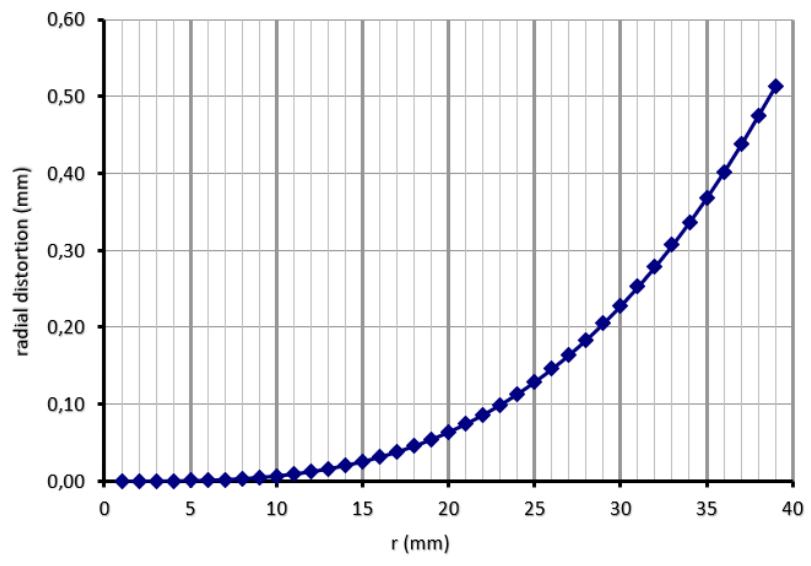

Figure 8. Radial distortion for $80 \mathrm{~mm}$ lens. 


\begin{tabular}{|c|c|c|c|}
\hline & $\begin{array}{c}\text { Calibration } \\
\text { protocol }\end{array}$ & $\begin{array}{c}\text { Calculated } \\
\text { value }\end{array}$ & $\Delta$ \\
\hline $\mathrm{f}[\mathrm{mm}]$ & 40.33 & 40.62 & 0,29 \\
\hline $\mathrm{pp} \_\mathrm{x}[\mathrm{mm}]$ & -0.11 & -0.15 & 0.04 \\
\hline $\mathrm{pp} \_\mathrm{y}[\mathrm{mm}]$ & 0.21 & 0.32 & 0.11 \\
\hline
\end{tabular}

Table 3. Results of camera calibration for $40 \mathrm{~mm}$ lens.

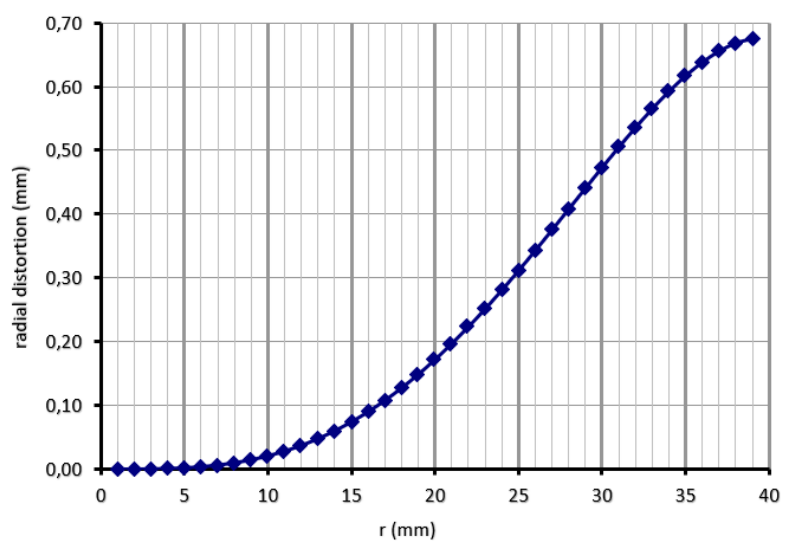

Figure 9. Radial distortion for $40 \mathrm{~mm}$ lens.

\section{CREATION OF 3D MODEL AND ORTHOPHOTO}

After georeferencing and analysis of photogrammetric model, dense point cloud was computed using all images. Each point in the point cloud represents survey point in denser detail then $5 \times 5 \mathrm{~m}$ grid which was set in 1994 measurement. Then 3D mesh model was created with the highest density. Texture from images was applied on the model and then the model of the quarry was divided into four parts (north, south, west, east). For each part an orthophoto was created with $0.02 \mathrm{~m} /$ pix resolution.

\begin{tabular}{|l|c|}
\hline Tie points [points] & 89835 \\
\hline Dense point cloud [points] & 180481164 \\
\hline Mesh [faces] & 36096232 \\
\hline Orthophoto [m/pix] & 0,02 \\
\hline
\end{tabular}

Table 4. Photogrammetric results.

\section{RESULTS}

The result of this paper is what accuracy is possible to expect with processing of historical analog images captured by Rollei 6006 metric camera while adhering the proposed methodology. The analysis has shown that the accuracy of original photogrammetric measurement is kept the same with structure from motion processing. The dense point cloud, 3D textured model and four orthophotos were created. All those results can provide much more detailed geological mapping than mapping carried out in 1994 and are much more understandable and easyto-use for geologists. Cross sections of model were carried out in selected parts and compared to cross sections from former measurements. That was used as survey points comparison.

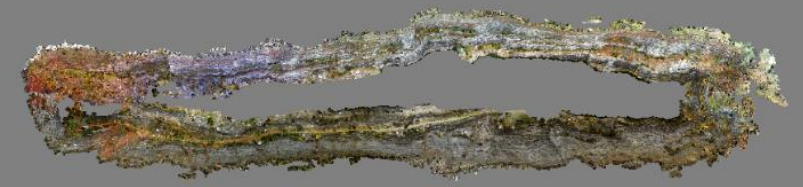

Figure 10. Dense point cloud of the Great America quarry.

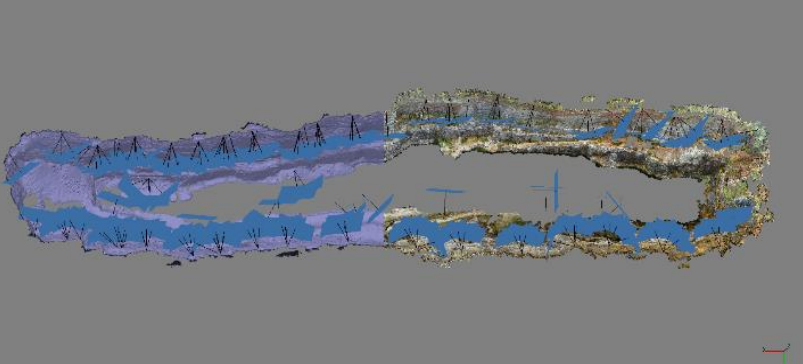

Figure 11.3D mesh and dense point cloud.

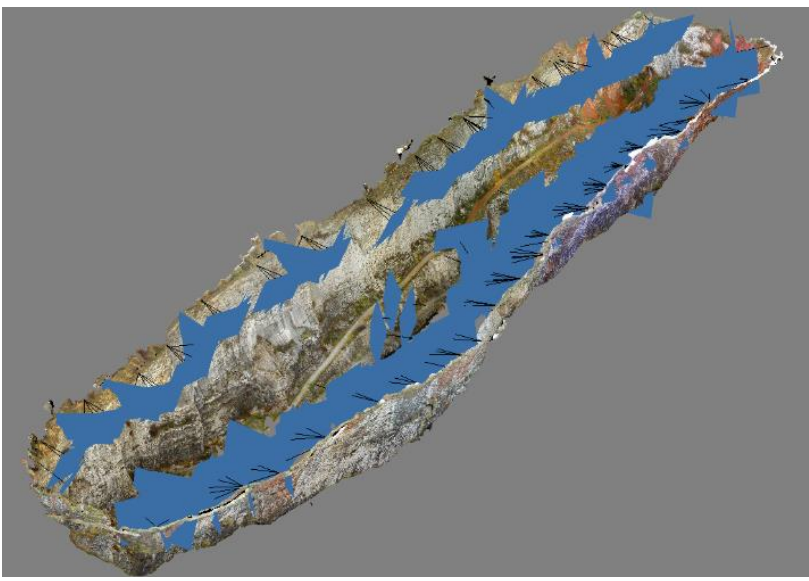

Figure 12.3D textured model of quarry's walls.

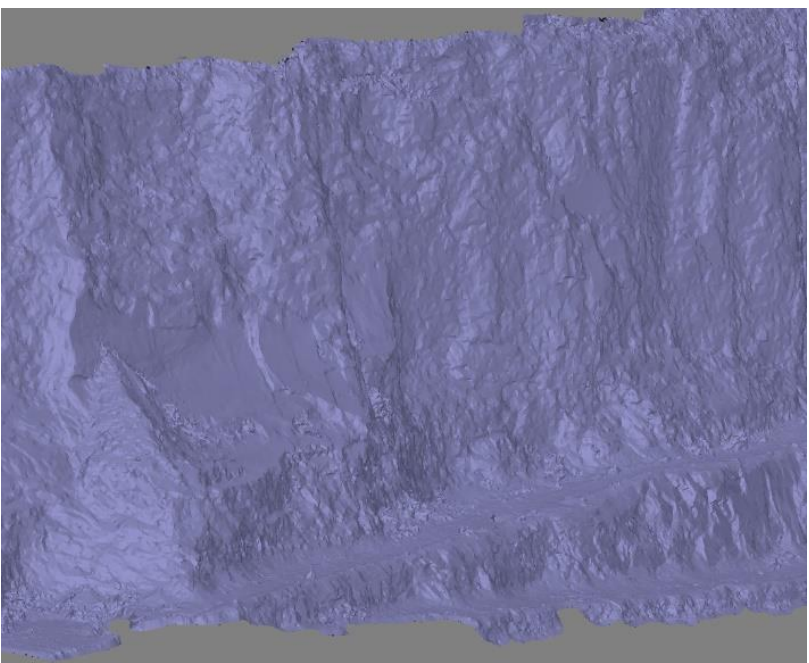

Figure 13. Part of 3D mesh of quarry's walls.

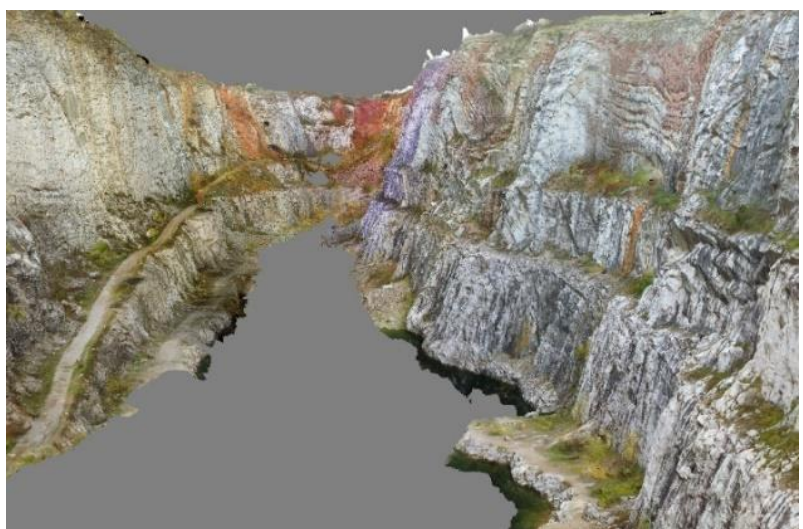

Figure 14. Part of 3D textured model of quarry's walls. 


\section{CONCLUSION}

The methodology of processing Rollei metric images using SfM method was proposed. For evaluation of this method archive images of the Great America quarry were chosen. The reason why this project was chosen was that negatives of more than 170 images captured by Rollei 6006 metric camera with two different lenses were available together with more than 300 geodetically measured and adjusted points and full calibration reports for both used lenses. Due to all these archived data the evaluation of methodology could be presented. The image negatives were scanned on non-photogrammetric scanner and the scanned images were transformed and cropped for further processing. The processing was carried out with SfM method. After co-registration of images 35 points were used as GCPs and 293 were used as control points for comparison. Newly calculated points were compared to adjusted points in 1994 and $68 \%$ of distances in space were under $5 \mathrm{~cm}$. $96 \%$ of the calculated distances were under $10 \mathrm{~cm}$. It could be declared that proposed methodology preserved original accuracy for mapping scale 1:500 and the testing was successful. The newly calibrated interior orientation of cameras was compared to values stated in calibration report. Those values have changed, and thus it will be subject to analysis in further research as well as processing the data in different software solutions. The robustness of the proposed methodology will be tested as well. The results have high visual quality, are easy-to-use and understandable for researchers from different fields of study. The presented methodology could be conveniently applied to many cultural heritage projects and there is a wide possibility to use an extensive amount of archival analog photogrammetric data and gather unique and highly valuable results. Data could be used in GIS, BIM and HBIM systems and are applicable in different kinds of rapidly developing fields as virtual reality, augmented reality and many other 3D applications.

\section{ACKNOWLEDGEMENTS}

This project was supported by grant of the Czech Technical University in Prague, "Analyses in geomatics: Processing spatial data about history and today", SGS18/056/OHK1/1T/11. This project is a part of internal research of EuroGV s.r.o. company.

\section{REFERENCES}

Luhmann, T.; Robson, S.; Kyle, S.; Harley, I., 2007. Close range photogrammetry. Wiley, pp. 142-146.

Maiwald, F.; Vietze, T.; Schneider, D.; Henze, F.; Münster, S.; Niebling, F., 2017. Photogrammetric Analysis of Historical Image Repositories for Virtual Reconstruction in the Field of Digital Humanities. In: The International Archives of the Photogrammetry, Remote Sensing and Spatial Information Sciences, Nafplio, Greece, Vol. XLII-2/W3, pp. 447-452.

Pavelka, K.; Šedina, J.; Raeva, P.; Hůlková, M., 2017. Modern Processing Capabilities of Analog data from Documentation of the Great Omayyad Mosque in Aleppo, Syria, Damaged in Civil War. In: The International Archives of the Photogrammetry, Remote Sensing and Spatial Information Sciences, Ottawa, Canada, Vol. XLII-2/W5, pp. 561-565.

Pavelka, K., 2011. Fotogrammetrie 2. Vydavatelství ČVUT, pp. 4-5.

Rodríguez Miranda, Á.; Valle Melón, J.M., 2017. Recovering old stereoscopic negatives and producing digital 3D models of former appearances of historic buildings. In: The International Archives of the Photogrammetry, Remote Sensing and Spatial Information Sciences, Nafplio, Greece, Vol. XLII-2/W3, pp. 601608 .

Styliadis, A.D., 2007. Digital documentation of historical buildings with 3-d modeling functionality. Automation in Construction, 16(4), pp. 498-510. 